\title{
The Implementation of Blended Learning Model to Learning Independence and Learning Outcomes of Vocational Students
}

\author{
Tohari. $\mathrm{H}^{1}$, Kudhori. $\mathrm{A}^{2}$, Pandowo. $\mathrm{H}^{3}$ and Sugiharto ${ }^{4}$ \\ State Polytechnic Madiun, Jl. Ring Road Barat Manguharjo Kota Madiun \\ \{htohari@pnm.ac.id\}
}

\begin{abstract}
This study was conducted to determine the effect of the implementation of the blended learning model to student learning independence and learning outcomes of vocational students' PBO. METHODS: This research uses quantitative methods. The results of this study indicate that (1) the percentage value of student learning independence PBO using the blended learning model is $61.72 \%$; (2) obtained the posttest mean (mean) value in the control class is 69.1250 , and in the experimental class is 78.2500 , and the results of the sign test obtained a significance value of 0.000 or a significance of $<0.05(0.000<0.05)$. Referring to these result, it can be concluded that from the implementation of the blended learning model on the PBO course, student's learning independence is in good criteria, and there is an affect on student's learning outcomes.
\end{abstract}

Keywords: Blended Learning, Independence Learning, Learning Outcomes.

\section{Introduction}

Education is a conscious and planned effort to make an atmosphere of learning and the learning process so that students actively to develop their potential to have religious spiritual strength, self-control, personality, intelligence, nobel character, and skills needed by themselves, society, nation and state [1]. Education has an important role in ensuring human development and survival, because basically education is an effort to prepare students for the future. The goals of national education according toz the Law of the Republic of Indonesia No. 20 of 2003 concerning the National Education System in Article 3 is to develop the potentialz of students to become humanzbeingsz who believe and fear God Almighty, have noble character, are healthy, knowledgeable, capable, creative, independence, and become democratic and responsiblez citizensz. answer. Politeknik Negeri Madiun (PNM) as a vocational higher education institution continues to be demanded to be able to realize these national education goals, one of the efforts that can be taken is through improvements in the learning process.

Choosing a learning model isz onez ofz thez important things inz the learning process, especially the zlearning processz in vocational education institutions. The learning model has an important contribution to the learning success of students, one of the indicators can be seen from their learning outcomes. Thezlearningzzmodelz is a packagezorzframe of an application of an approach,zmethod, andztechnique in implementing learning [2][3]. There are several zlearning models, onez ofz them is thezBlendedz Learningz model. Blendedz learningz can be 
said to be a learning process that utilizes various approaches. Approaches can be made by utilizing various media and technologies. In simple terms, it can be said that blendedz learningz is learningz that combinesz zlearning deliveryzstrategieszusingzface-tofacezactivities, offline computer-basedzzlearning, and online computer-based learning.

The Object Oriented Programming course (PBO) is a course in the form of a practice / practicum, which is carried out with azface-to-face learningzmodel inza computer laboratory. According to the results of the evaluation that has been done,ZitZcan Zbe Zconcluded thatZstudent learningZoutcomesZforZtheseZ courses areZstill not optimal. This condition is very likely influenced by the learning model used, because according to the results of initial observations made by the lecturer / laboratory assistant concerned, it is stated that students look quickly bored / bored when they have to do hours of practice / practicum in the computer laboratory.

A study entitled "An EmpiricalzEvaluationzofzCritical FactorszInfluencingzLearnerzSatisfactionzin Blended Learning: A Pilot Study" by [4] stated that students (millennial generation) prioritize design aspects as the main factor. Their satisfaction with the components of e-learning in a blended learning environment. Therefore, it is more strategic for educational institutions to emphasize the design dimension in their elearning implementation in a special blended learning environment for younger students.

Observing the advantages of blended learning, the results of research by [5] entitled "Development of a Blended Learning Model for Learning Technology Planning, Information and Communication Technology Planning Courses" show that the development of a blended learning model can be improve learning outcomes so that it can make it easier for students to understand the material presented, either through traditional learning or using e-learning media.

Agreezwith the results of these two studies, the research entitled "Application of Blended Learning Strategies to Improve Students'zCriticalzThinkingzAbilityzinzthe IndustrialzRevolutionzEraz4.0" by [6], states that the blended learning strategy can be used as one of the new learning innovations that follow the development of learning technology in the era of 4.0. Learning is no longer only taking place face-to-face in class but can be combined with online learning.

Agree with the results of the three studies; so, here can be said that using azblendedzlearningzmodel is an implementationzofzlearningzthat combineszface-to-face learningzandzonline learning through various media in which the bleanded learning model can foster students' critical thinking skills so that it can improve student learning outcomes.

Based on that background, this research was conducted tozdescribezthezlearning independence ofzstudents who use the blended learning model in PBO courses, and knowing whether or not there is an effect of the implementation of the blended learning model in PBO courses on student learning outcomes.

\section{Literature review}

This research uses the several fundamental theories. These theories are about blended learning model, independence learning, and learning outcomes.

\subsection{Blended learning model}

Blendedz learningz iszazlearningzmodel thatzcombines the strengths of traditionalzfaceto-face learning with an electronic learning environment [7]. The implementation of learning 
that occurs in conventional classrooms where educatorszandzstudentszmeetzface to face,zwithzonline learningzthatzcan bezaccessed anytime and anywhere. Another form ofzblended learningzis a virtual meeting betweenzzeducatorszandzstudents.[8] Thezblendedzlearning is learning which combines two methods namely face-to-face learning online [6]. According to several theories about thezblended learningzmodel,zblendedzlearning canzbe expressedzasza learningzprocess that utilizes various approaches. The approach taken can take advantage of various media and technologies. Thezelements ofzblendedzlearningbased learningzcombinezface-to-facezand e-learning which has 6 (six) elements, namely: (a) face-to-face (b) independence learning, (c) application, (d) tutorial, (e) collaboration , and (f) evaluation (see: fig.1).

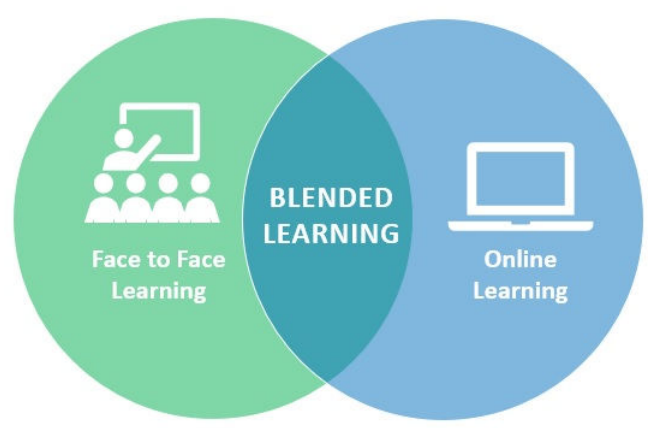

Fig. 1. Ilustration of blended learning

\subsection{Learning independence}

Learningzindependenceziszanzactivezlearningzactivity thatziszdrivenzbyzazmotivezto master azcompetency, which is built with the knowledge or competencies that you already have (Mudjiman, 2011:1).[9] Learning independence activities familiarize students to apply active and participatoryzlearningzto developzthemselveszindividually who are not bound by the presencezof teachers and classmates; students are free to determine the direction, plans, resources, and decisions to achieve academic goals [10].

According to those theories, it can be stated that independence in learning or learning independence is a method used by educators to accustom students to active learning to master a competency that is built from the knowledge they have. The role of an educator in independence learning is only as a facilitator and is not the only source of knowledge. The characteristics of independence can be distinguished aszfollows: (1) Emotionalzautonomy, an aspect ofzindependence that states changes inzemotional closenesszbetweenzindividuals, such as the emotional relationship ofzstudentszwithzteacherszorztheir parents. (2) Independence behavior (behavioral autonomy), An ability to make decisions without depending on others and do it responsibly. (3) autonomy value, the ability to interpret a set of principles about right and wrong, about what is important and what is not important [11].Learning independence consists of three aspects, namely learning management, responsibility, and the use of various learning resources.[12] The aspects of independence learning consist of: 1) Stand alone, 2) Solve problems, 3) Responsibility, 4) Initiative and creativity.[13] The characteristics of independence learning are: 1) independence of others, 2) having self-confidence, 3) behaving in discipline, 4) havingzazsensezofzresponsibility, 5) behavingzbasedzon one'szownzinitiative, 6) exercising self-control [14]. With some of the opinions mentioned above, it can be stated 
that the aspects of learning independence include: 1) initiative, 2) self-confidence, 3) motivation, and 4) responsibility.

\subsection{Learning outcomes}

Learningzoutcomeszarezessentiallyzazchange in behavior. Behavior as a result of learning in a broad sense includes the cognitive, affective, zandzpsychomotor fields [15]. ZLearningzoutcomesZareZabilitiesZobtained by studentszafterzgoingzthroughZprocessZof learningzactivities.[16] Learning outcomes are abilities that children acquire after going through learning activities. The learning activity itself is a process of someone trying to obtain a form of change inzbehavior that is relatively sedentary.[17]

So, the learningZoutcomesZareZthe results obtainedZby students afterZZtheZlearningzprocess is indicated by the test scores given by the lecturer after each giving lecture material on one subject. Learning outcomes are not only in the form of values, but can be in the form of changes in behavior that lead to positive changes.

\section{Method}

This research is applied research, and this reseach using quantitative method. According to the research design (see: fig.1), this research uses the following formula[18]:

Table 1. Posttest-Only Control Design

\begin{tabular}{lcc}
\hline \multicolumn{1}{c}{ Class } & Treatment & Posttest \\
\hline Exsperiment & $\mathrm{X}$ & $\mathrm{O}_{1}$ \\
Control & - & $\mathrm{O}_{2}$ \\
\hline
\end{tabular}

$\mathrm{O}_{1}$ : Posttest scores from the experimental class

$\mathrm{X}$ : The treatment uses Blended Learning as a learning model

$\mathrm{O}_{2}$ : Posttest scores from the control class

This research was conducted from March to August 2020. The research location was conducted in the Computerized Accounting Study Program, more precisely in the Accounting Computerized Study Program-PNM. The research subjects used for this study were students from the Accounting Study Program of PNM. These students will be treated as respondentsZin ZtheZcontrol classZandZexperimentalZclass. ThereZare two data collection techniques used in the implementation of this research. These techniques are questionnaires and tests, while the test used is a formative test. Referring to the predetermined problem formulations, two tests will be carried out, these tests are:

\subsection{The level of student learning independence that using the blended learning model}

The way to determine the level of learning independence is calculated using the percentage formula as bellow:

$P=\frac{\text { jumlah alternatif jawaban yang dipilih dari setiap aspek }}{(\text { skor tertinggi likert } x \text { jumlah butir soal) xjumlah responden }} \times 100 \%$ 
The meaning of the proportion valueZasZaZresultZof calculationsZusingZthiszformulazwhich will determine whether the questionnaire results show a positive or negative value, thatzdeterminedZbasedZonZtheZLikert scale criteriaZshown Zin Ztable 2.

Table 2. Score Criteria

\begin{tabular}{|c|c|}
\hline Persentage & Criteria \\
\hline $81 \%-100 \%$ & Very high \\
\hline $61 \%-80 \%$ & High \\
\hline $41 \%-60 \%$ & Middle \\
\hline $21 \%-40 \%$ & Low \\
\hline $0 \%-20 \%$ & Very low \\
\hline
\end{tabular}

\subsection{The effect of using the blended learning model to student learning outcomes}

Thezanalysiszof the test result iszusedzto compare the acquisition of students learning outcomes using the blended learning model with thezlearningZoutcomesZofZstudents who do not use the blended learning model through the learning outcomes obtained from the posttest implementation. While the test result score criteria are shownzinztable 3.

Table 3. The criteria of test result

\begin{tabular}{cc}
\hline Test Result & Criteria \\
\hline $81-100$ & Very high \\
\hline $61-80$ & High \\
\hline $41-60$ & Middle \\
\hline $21-40$ & Low \\
\hline$<21$ & Very low \\
\hline
\end{tabular}



Fig.2. Research design 
According to the research stages (see:fig.2), the researchers set a research paradigm for this study as shown in fig.3. Based on the research paradigm in this study (see: fig.2), the following research hypotheses can be established:

a) $\mathrm{H}_{\mathrm{o}}$ : Students who use the blended learning model in PBO courses, their learning independence is not very good.

b) $\mathrm{H}_{\mathrm{a}}$ : Students who use the blended learning model in PBO courses have very good learning independence.

c) $\mathrm{H}_{\mathrm{o}}$ : Therezis nozeffect of the implementation ofzthe blended learningzmodel in PBO courses on student learning outcomes.

d) $\mathrm{H}_{\mathrm{a}}$ : Therezis anzeffect of the implementation of the blended learningzmodel in PBO courses on student learning outcomes.

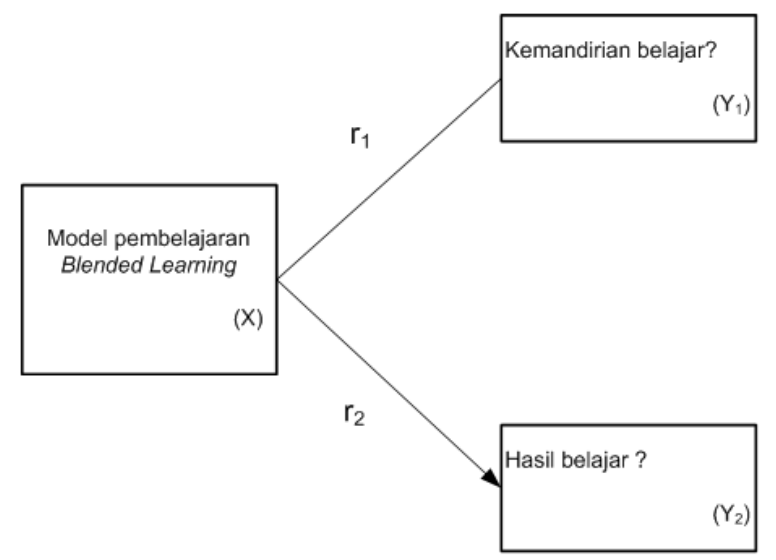

Fig. 3. Research paradigm

\section{Result}

\subsection{The Analysis of the Level of Student Learning Independence}

The level of independence test carried out is in the form of aznon-test to determine the student's learning independence. Thezlearning independence questionnaire was given to the posttest group, which aims to determine the student's learning independence after being given treatment. According tozthe result of questionnaire calculation, thezalternative answers chosen from each aspect chosen by the respondent were 1975, where the highest Likert score was 4, with $\Sigma$ statement items in the questionnaire being 20 statement items, and $\Sigma$ respondents as many as 40 students, then the results were obtained. the calculation of the learning independence questionnaire after using the blended learning model is as bellow:

$P=\frac{1975}{3200} \times 100 \%=61,72$

According tozthe resultszof the learning independence questionnairezgiven to students using the blended learning model in PBO courses, it can be seen that the percentage value obtained is $61.72 \%$. The results of the questionnaire calculation are in the Good score criteria. 
It is necessary to note that in this study researchers did not pay attention to things that could affect learning independence. Agree with [3] who state that the design dimension is The most important factor of student satisfaction is the e-learning components in the blendedzlearning environment, so it is morezappropriatezforzeducational institutions (including for PNM) to emphasize the design aspects of the application of e-learning which emphasizes a mixed learning model that aims to develop learning independence students.

\subsection{The Analysis of Differences in Learning Outcomes}

The analysis to determine whether thereziszanzeffect or not fromzthe applicationzof the blended learning model in PBO learning on student learning outcomes is used the two mean similarity test; Through this test the posttest results will be compared after learningZbetweenZthe controlZclassZandZtheZexperimentalZZclass. The subjects for the control class were 40 students, and for the experimental class there were 40 students. The calculation of the two mean similarity test was carried out using the independence sample ttest. The $t$-test was carried out using the SPSS application tool, with the results as shown in fig.4.

T-Test
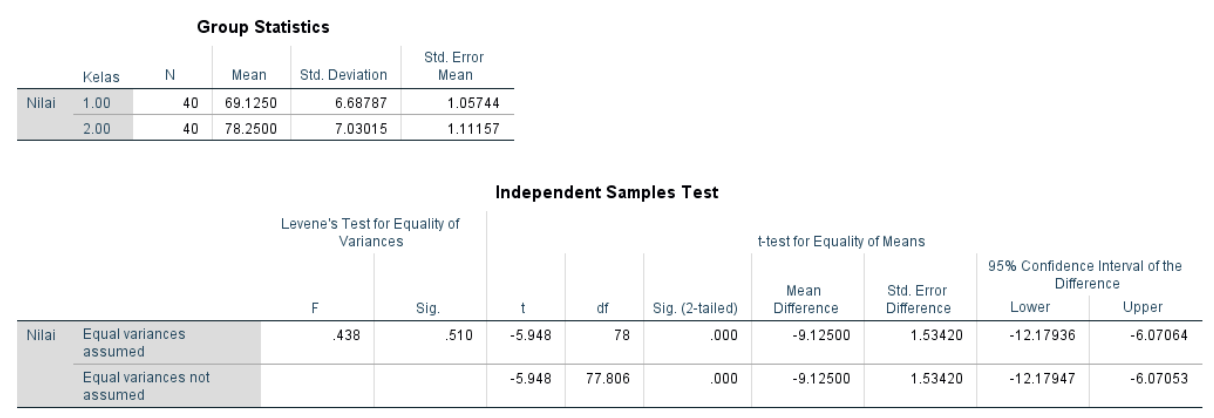

Fig. 4. The results of the two mean similarity test

According to the results of the calculations as shown in table 4, it can be seen that the posttest mean (mean) in the controlzclasszis 69.1250, andzinzthezexperimental class is 78.2500. Then, the results of the calculation using thezsignztest obtained a significance value based on the asympzcolumn. Sig (2-tailed) zof 0.000 orzsignificance $<0.05(0.000<0.05)$. So, it canzbezseen thatzthere is a difference in the average posttest score in the control class and the average posttest score in the experimental class. Accordingztozthe resultsZofZtheZsignZZtest, it can be seenZthatZthe results of the posttest in the control class that do not use the blended learning model and the experimental class using the blendedzlearningzmodel, it can be said there iszanzeffect ofzdifferences in learning outcomes in PBO courses for fourth semester students of Computerized Accounting Study ProgramPNM.

As research conducted by [5]which shows that the developmentzofzazblendedZlearningZmodelZcan improveZstudent learningZoutcomesZand it isZeasierZto understandZtheZmaterialZthrough both classical learning and using e-learning, thus it would be more appropriate if the blended learning model was also developed and 
implemented in learning in the Computerized Accounting Study Program-PNM as an effort to improve student learning outcomes.

\section{Conclusions}

According to data analysis and discussion of the results of the analysis, the following conclusions can be drawn:

a) Students who use the blended learning model in the PBO subject of their learning independence are not in very high criteria, but are in high criteria $\left(\mathrm{H}_{\mathrm{o}}\right.$ is proven/accepted).

b) Therezis an effect of the implementation of the blended learning model in PBO courses on student learning outcomes $\left(\mathrm{H}_{\mathrm{a}}\right.$ proven/accepted $)$.

Table 4. Appendix A The result of students' learning independence questionnaire

\begin{tabular}{|c|c|c|c|c|c|c|}
\hline \multirow[t]{2}{*}{ No } & \multicolumn{4}{|c|}{ Score } & \multirow[t]{2}{*}{ Sum of respondent } & \multirow[t]{2}{*}{ Sum of score } \\
\hline & 4 & 3 & 2 & 1 & & \\
\hline 1 & 10 & 15 & 10 & 5 & 40 & 110 \\
\hline 2 & 0 & 17 & 4 & 19 & 40 & 78 \\
\hline 3 & 1 & 2 & 10 & 27 & 40 & 57 \\
\hline 4 & 0 & 19 & 10 & 11 & 40 & 88 \\
\hline 5 & 0 & 20 & 5 & 15 & 40 & 85 \\
\hline 6 & 0 & 16 & 4 & 20 & 40 & 76 \\
\hline 7 & 15 & 16 & 9 & 0 & 40 & 126 \\
\hline 8 & 0 & 8 & 13 & 19 & 40 & 69 \\
\hline 9 & 0 & 15 & 5 & 20 & 40 & 75 \\
\hline 10 & 19 & 1 & 9 & 11 & 40 & 108 \\
\hline 11 & 1 & 10 & 15 & 14 & 40 & 78 \\
\hline 12 & 0 & 26 & 10 & 4 & 40 & 102 \\
\hline 13 & 5 & 10 & 20 & 5 & 40 & 95 \\
\hline 14 & 20 & 10 & 10 & 0 & 40 & 130 \\
\hline 15 & 10 & 0 & 10 & 20 & 40 & 80 \\
\hline 16 & 2 & 18 & 15 & 5 & 40 & 97 \\
\hline 17 & 30 & 9 & 1 & 0 & 40 & 149 \\
\hline 18 & 20 & 10 & 9 & 1 & 40 & 129 \\
\hline 19 & 14 & 17 & 8 & 1 & 40 & 124 \\
\hline 20 & 15 & 13 & 8 & 4 & 40 & 119 \\
\hline
\end{tabular}

Table 5. Appendix B. The posttest result

\begin{tabular}{ccc}
\hline No & Control class & Experiment class \\
\hline 1 & 70,00 & 80,00 \\
2 & 70,00 & 65,00 \\
3 & 80,00 & 70,00 \\
4 & 75,00 & 70,00 \\
5 & 60,00 & 90,00 \\
6 & 60,00 & 90,00 \\
7 & 65,00 & 85,00 \\
8 & 65,00 & 80,00 \\
9 & 70,00 & 85,00 \\
10 & 70,00 & 75,00
\end{tabular}




\begin{tabular}{ccc}
\hline No & Control class & Experiment class \\
\hline 11 & 75,00 & 70,00 \\
12 & 85,00 & 70,00 \\
13 & 80,00 & 85,00 \\
14 & 70,00 & 85,00 \\
15 & 60,00 & 75,00 \\
16 & 70,00 & 75,00 \\
17 & 55,00 & 80,00 \\
18 & 60,00 & 95,00 \\
19 & 65,00 & 90,00 \\
20 & 65,00 & 80,00 \\
21 & 70,00 & 75,00 \\
22 & 75,00 & 80,00 \\
23 & 75,00 & 80,00 \\
24 & 80,00 & 80,00 \\
25 & 75,00 & 75,00 \\
26 & 75,00 & 70,00 \\
27 & 70,00 & 75,00 \\
28 & 65,00 & 80,00 \\
29 & 60,00 & 85,00 \\
30 & 70,00 & 85,00 \\
31 & 65,00 & 80,00 \\
32 & 65,00 & 85,00 \\
33 & 70,00 & 75,00 \\
34 & 65,00 & 75,00 \\
35 & 70,00 & 75,00 \\
36 & 65,00 & 70,00 \\
37 & 80,00 & 80,00 \\
38 & 65,00 & 70,00 \\
39 & 70,00 & 70,00 \\
\hline 40 & 65,00 & 70,00 \\
\hline & &
\end{tabular}

\section{Acknowledgements}

Thanks to research center-PNM (P3M-PNM) and Accounting Computerized DepartmentPNM who have facilitated researchers to conduct this research.

\section{References}

